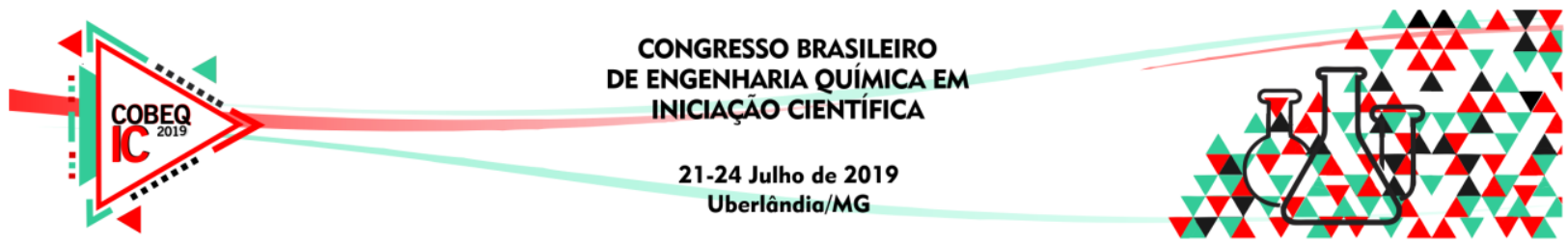

\title{
REDUÇÃO DA CONCENTRAÇÃO DE HIDRÓXIDO DE SÓDIO UTILIZADA EM SOLUÇỖES CIP: ESTUDO DE CASO
}

\author{
W. V. PEREIRA JUNIOR ${ }^{1}$, L. D. SILVA ${ }^{1}$ e R. GEDRAITE ${ }^{1}$ \\ ${ }^{1}$ Universidade Federal de Uberlândia, Faculdade de Engenharia Química \\ E-mail para contato: rgedraite@ufu.br
}

\begin{abstract}
RESUMO - Este trabalho teve como objetivo realizar um estudo de caso para possibilitar uma melhoria no sistema de limpeza denominado Clean in Place (CIP) de uma fábrica de sucos em Minas Gerais. O foco do trabalho foi verificar se as concentrações de hidróxido de sódio das soluções de limpeza utilizadas pela empresa estavam dentro dos valores usuais da literatura e, caso negativo, propor novas faixas de concentrações, de forma a garantir a qualidade de limpeza e evitar desperdícios de recursos.
\end{abstract}

\section{INTRODUÇÃO}

A intensa urbanização ocorrida nos últimos anos aumentou expressivamente o consumo de alimentos industrializados e, com isso, aumentou-se também a preocupação quanto a maneira que estes alimentos estão sendo produzidos para atender tamanha demanda. Com isto, os órgãos de vigilância passaram a exigir um controle de qualidade mais rigoroso, que incluem uma melhor higienização dos equipamentos para reduzir a capacidade de multiplicação dos microrganismos e evitar a contaminação (ANDRADE, 2008).

Desde então, não são poupados esforços para assegurar que o processo de higienização dos equipamentos seja adequado ao estabelecido na legislação em vigor. Entretanto, este fato tradicionalmente implica na utilização, por parte da comunidade industrial, de maior quantidade de soluções de limpeza do que o necessário e tecnicamente suficiente para atender aos requisitos.

O método de higienização dos equipamentos mais utilizado atualmente nas indústrias de bebidas e alimentos é o sistema de limpeza interna por circulação de soluções, conhecido como Clean in Place (CIP), composto pelas seguintes etapas: enxágue inicial, circulação de detergente alcalino, enxágue intermediário, circulação de solução ácida e um outro enxágue para eliminar qualquer resíduo de detergente ou sujidade. Dentre as fases do CIP, a que tem maior importância em aspectos de qualidade é a fase de circulação de solução alcalina, visto que é a que elimina os resíduos orgânicos, os maiores responsáveis pela contaminação dos produtos. Além disso, essa fase é realizada com maior frequência que a circulação de solução ácida, portanto, gera a maior parte dos resíduos e consome mais água, soluções detergentes e tempo do que as demais fases (TAMIME, 2008).

Diante desse contexto, um estudo sobre a concentração ótima de detergente alcalino nas soluções de limpeza de equipamentos industriais se mostra necessário para reduzir os riscos de contaminação e aprimorar o uso dos recursos. 


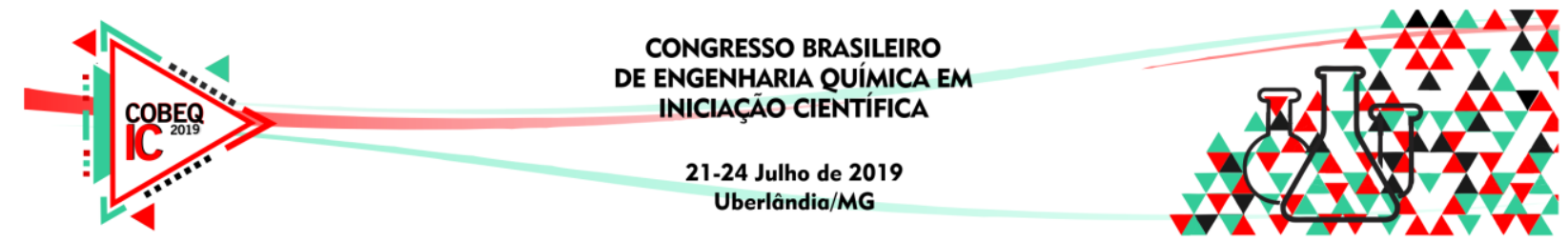

\section{REVISÃO BIBLIOGRÁFICA}

Segundo Plett (1985) concentrações altas de hidróxido de sódio atrapalham na remoção de resíduos, isso devido a um inchaço do depósito, denominado "depósito vítreo" que inibe o transporte. Christian (2004), realizando experimentos com três velocidades diferentes, verificou valores de concentração que otimizam o tempo de limpeza de equipamentos com depósitos de proteína de leite, conforme mostra a Figura 1, a qual é possível notar que, o aumento da concentração de solução de hidróxido de sódio contribui para reduzir o tempo de limpeza até aproximadamente $0,5 \% \mathrm{NaOH}$ p/p, mas que, acima desse valor o tempo tende a se estabilizar ou aumentar.

Figura 1 - Variação do tempo de limpeza com vazão e concentração de $\mathrm{NaOH}$.

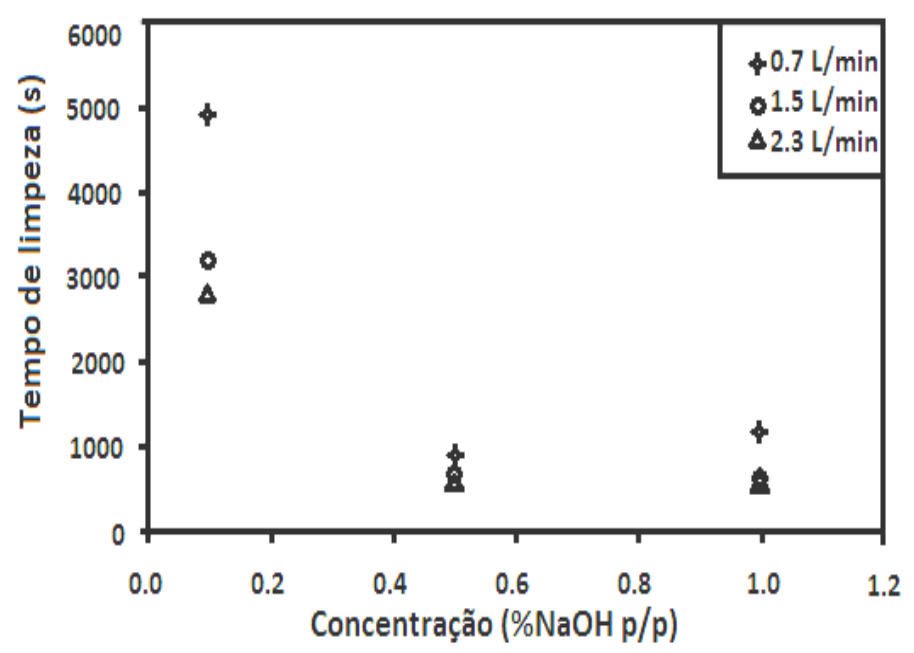

Fonte: CHRISTIAN (2004)

Segundo a Tetrapak (2004), o hidróxido de sódio é tipicamente utilizado com concentrações variando entre 0,5 a $2,0(\% \mathrm{NaOH}$ p/p) para a maioria das indústrias de processamento de sucos. Entretanto, a concentração de solução de limpeza não deve ser analisada separadamente pois, caso haja deficiências na vazão, temperatura ou tempo de circulação, é necessário que tais deficiências sejam compensadas com um acréscimo na concentração de produto alcalino. Essa interação entre os quatro fatores foi estabelecida pela primeira vez por Sinner (1960), e é representada na Figura 2.

Figura 2 - Representação da interação entre os parâmetros de limpeza.
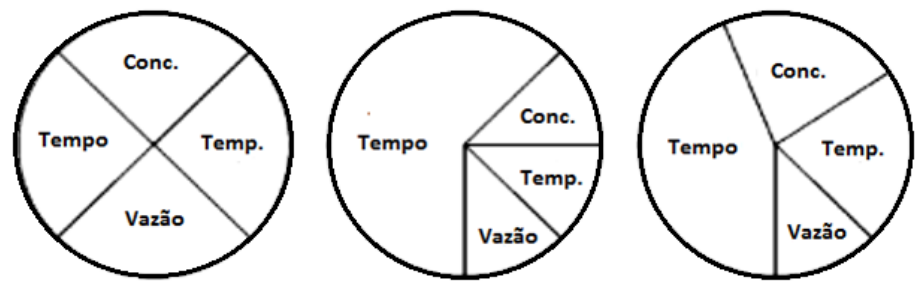

Fonte: LELIEVELD et al., (2005)

Iniciando por uma análise da vazão de escoamento, um estudo realizado por Timperley e Smeulders (1988) mostrou que o tempo de limpeza reduz com o aumento da velocidade 


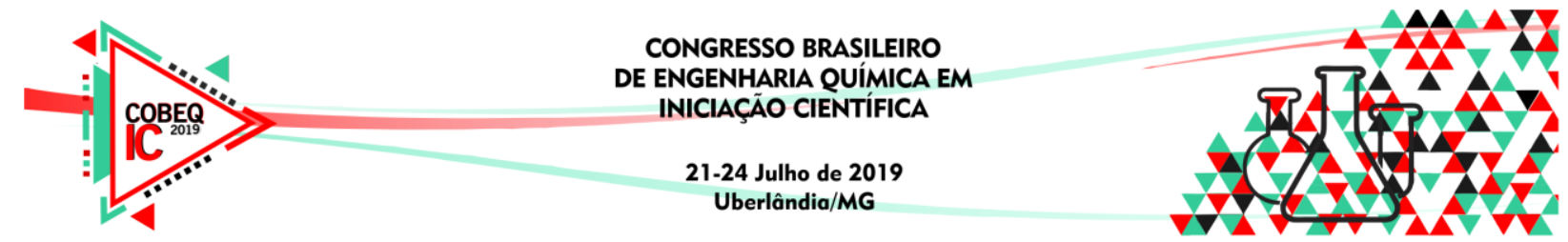

média de solução, porém, a taxa de melhoria diminui à medida que a velocidade aumenta, até ocorrer uma assíntota em torno de 1,5 m/s, como pode ser visto na Figura 3.

Figura 3 - Efeito da velocidade no tempo de limpeza.

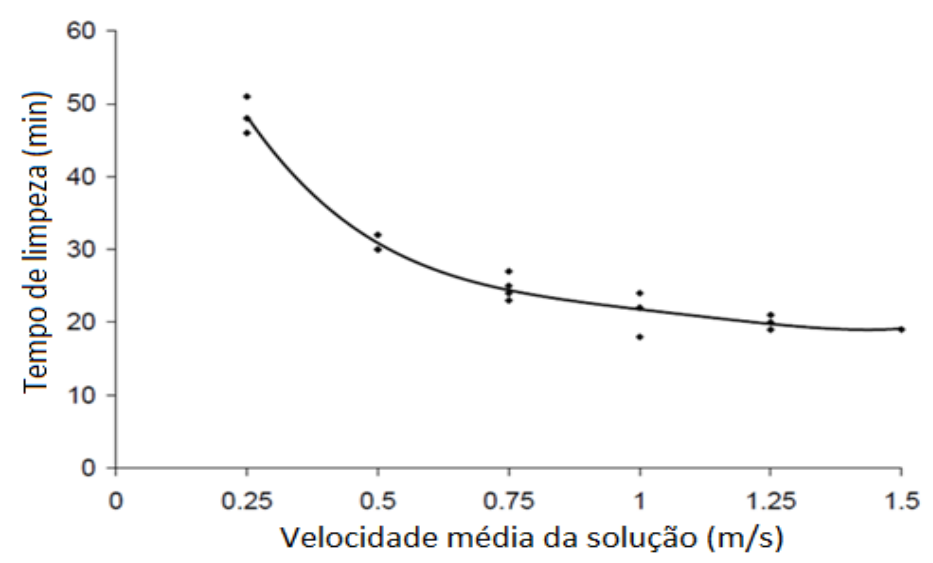

Fonte: TIMPERLEY; SMEULDERS (1988)

Assim, vazões correspondentes a uma velocidade média de $1,5 \mathrm{~m} / \mathrm{s}$ tem sido usadas desde então para CIP em muitas instalações de processamento de alimentos, se mostrando eficientes na limpeza (LELIEVELD et al., 2005).

Com relação a temperatura, em geral, à medida que ela aumenta, a taxa de limpeza aumenta, pois reduz a tensão superficial e a viscosidade da solução de limpeza, além de aumentar a velocidade de reação entre os detergentes e a sujidade. Porém, um aumento exagerado na temperatura pode ocasionar mudanças na estrutura dos resíduos, como a desnaturação de proteínas, ou ocasionar mudanças nas propriedades dos detergentes, especificamente na estabilidade física, formando precipitados ou filmes. Portanto, como regra geral, um equipamento deve ser limpo na mesma temperatura em que se está processando os alimentos (LELIEVELD et al., 2005; TETRA PAK, 2015).

Já no que se refere ao tempo, ele precisa ser o suficiente para permitir dissolução, arraste e remoção das sujidades, incluindo todas as fases do processo de limpeza até obter uma superfície completamente livre de qualquer tipo de resíduos. Porém, incrementar o tempo de limpeza não é uma escolha tão simples, visto que é um recurso crucial na indústria e que poderia ser utilizado para aumentar a produção (TAMIME, 2008).

$\mathrm{Na}$ Tabela 1 são encontrados alguns exemplos comuns de temperatura e tempo referentes a etapa de circulação de solução alcalina em indústrias de suco de laranja (TETRA PAK, 2004).

Tabela 1 - Exemplos de temperatura e duração de cada etapa do CIP.

\begin{tabular}{|c|c|c|}
\hline $\begin{array}{c}\text { Tipos de } \\
\text { superfícies }\end{array}$ & $\begin{array}{c}\text { Temperatura } \\
\left({ }^{\circ} \mathrm{C}\right)\end{array}$ & $\begin{array}{c}\text { Tempo } \\
(\mathrm{min})\end{array}$ \\
\hline \hline Não aquecidas & Ambiente & 10 \\
\hline Aquecidas & 70 & 20 \\
\hline
\end{tabular}

Fonte: TETRA PAK (2004) 


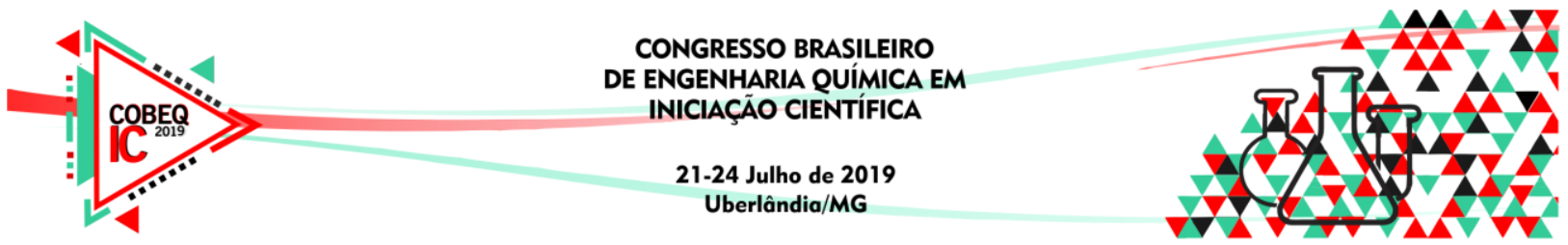

\section{MATERIAIS E MÉTODOS}

Primeiramente coletou-se as informações de temperatura, tempo, vazão e concentração referentes a etapa de circulação de solução alcalina para todos os equipamentos da unidade em estudo, como pode ser visto na Tabela 1.

Tabela 2 - Parâmetros estabelecidos para a etapa de circulação alcalina de cada equipamento.

\begin{tabular}{|c|c|c|c|c|c|c|}
\hline \multirow{2}{*}{ Equipamentos } & Linha & $\begin{array}{c}\text { Tipos de } \\
\text { superfície }\end{array}$ & $\begin{array}{c}\text { Temperatura } \\
\left({ }^{\circ} \mathrm{C}\right)\end{array}$ & $\begin{array}{c}\text { Tempo } \\
(\mathrm{min})\end{array}$ & $\begin{array}{c}\text { Vazão } \\
\left(\mathrm{m}^{3} / \mathrm{h}\right)\end{array}$ & $\begin{array}{c}\text { Concentração } \\
(\% \text { kg det. / } \\
\text { litro solução })\end{array}$ \\
\hline \hline \multirow{4}{*}{$\begin{array}{c}\text { Máquinas de } \\
\text { envase }\end{array}$} & PET & Aquecida & 85 & 35 & 20 & $2,0-2,5$ \\
\cline { 2 - 7 } & Cartonado 1 & Aquecida & 65 & 25 & 16 & $2,0-2,5$ \\
\cline { 2 - 7 } & Cartonado 2 & Aquecida & 65 & 25 & 16 & $2,0-2,5$ \\
\cline { 2 - 7 } & Cartonado 3 & Aquecida & 65 & 25 & 16 & $2,0-2,5$ \\
\hline \multirow{4}{*}{ Pasteurizadores } & PET & Aquecida & 90 & 30 & 26 & $3,5-5,0$ \\
\cline { 2 - 7 } & Cartonado 1 & Aquecida & 85 & 30 & 16 & $2,0-2,5$ \\
\cline { 2 - 7 } & Cartonado 2 & Aquecida & 85 & 30 & 16 & $2,0-2,5$ \\
\hline Turbo extrator & Extração & Não aquecida & Ambiente & 25 & 12 & $2,0-2,5$ \\
\hline Tanques & Envio MP & Não aquecida & Ambiente & 30 & 12 & $2,0-2,5$ \\
\hline Tanque & Xaroparia & Não aquecida & Ambiente & 25 & 12 & $2,0-2,5$ \\
\hline Tanques & Formulação & Não aquecida & Ambiente & 25 & 12 & $2,0-2,5$ \\
\hline
\end{tabular}

Antes de uma análise detalhada da concentração de detergente foi verificado se os parâmetros atuais de tempo, temperatura e vazão estão bem definidos.

Os parâmetros de tempo e temperatura utilizados pela empresa estão em concordância com a literatura, visto que, todos os tempos de recirculação adotados pela empresa são maiores que 20 minutos e nos equipamentos que operam com aquecimento, as temperaturas de limpeza são as mesmas das que se processam os alimentos e estão próximas do valor usual de $70^{\circ} \mathrm{C}$. Para análise de vazão, foi observado o ponto de diâmetro máximo dos equipamentos, por ser onde a velocidade atinge seu mínimo valor. Na unidade estudada, todas as tubulações dos equipamentos de envase e pasteurização possuem diâmetro nominal máximo de 2,5 polegadas e nas linhas não aquecidas, o diâmetro nominal máximo é de 2 polegadas. Sabe-se que, as vazões necessárias para gerar uma velocidade de $1,5 \mathrm{~m} / \mathrm{s}$ nessas condições são respectivamente, $15,4 \mathrm{~m}^{3} / \mathrm{h}$ e $9,9 \mathrm{~m}^{3} / \mathrm{h}$. Então, retornando à Tabela 2, percebe-se que todas as vazões utilizadas nos equipamentos proporcionam velocidades superiores à sugerida pelos estudos, ou seja, a vazão de escoamento não é um fator que deve ser compensado.

Consequentemente, se não há problemas quanto ao tempo, temperatura e nem quanto a vazão de escoamento, pode-se concluir que as concentrações podem estar entre 0,5 e $2,5 \%$ $\mathrm{p} / \mathrm{p} \mathrm{NaOH}$ conforme proposto pela literatura.

Realizando-se a conversão dos valores usuais para valores de concentração em peso de detergente alcalino por volume de solução, já que na fábrica não é utilizado $\mathrm{NaOH}$ em sua forma pura, mas sim como um detergente formulado com alcalinidade de 42,6\%(p/p), através da Equação 1 e da Equação 2, tem-se que os valores mínimo e máximo indicados para a concentração deste detergente são respectivamente $1,17 \%(\mathrm{p} / \mathrm{v})$ e 4,64 (\%p/v). 


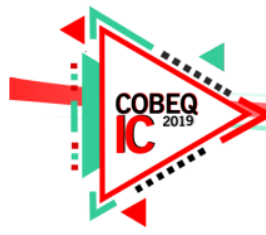

$\frac{0,5(\mathrm{~kg} \mathrm{NaOH}) \times 1(\mathrm{~kg} \text { solução }) \times 1(\mathrm{~kg} \text { detergente })}{100(\mathrm{~kg} \text { solução }) \times 1,003(\text { L solução }) \times 0,426(\mathrm{~kg} \mathrm{NaOH})} \times 100 \%=1,17 \% \frac{\mathrm{kg} \text { detergente }}{L \text { solução }}$

$$
\frac{2,0(\mathrm{~kg} \mathrm{NaOH}) \times 1(\mathrm{~kg} \text { solução }) \times 1(\mathrm{~kg} \text { det ergente })}{100(\mathrm{~kg} \text { solução }) \times 1,011(\text { L solução }) \times 0,426(\mathrm{~kg} \mathrm{NaOH})} \times 100 \%=4,64 \% \frac{\mathrm{kg} \text { detergente }}{L \text { solução }}
$$

Na tabela 1 é possível observar que em todos os equipamentos são utilizadas concentrações entre 2,0 e $2,5 \%$ p/v de detergente, com exceção do pasteurizador PET que utiliza concentrações mais elevadas $(3,5$ a $5,0 \%$ p/v). Deste modo, nota-se que há possibilidade de redução na faixa de concentração do pasteurizador PET, já que ultrapassa o valor máximo indicado de 4,64 \%(p/v), o que é arriscado em termos de qualidade por formar um depósito vítreo. Além disso, uma outra possibilidade de alteração é nas linhas sem aquecimento, por apresentarem baixo teor de incrustações.

Assim, propõe-se para a empresa, adotar um limite superior no pasteurizador de 4,5\% $(\mathrm{p} / \mathrm{v})$ e um limite inferior nas linhas frias de $1,5 \%(\mathrm{p} / \mathrm{v})$, para que se possa realizar uma limpeza efetiva utilizando-se de menor quantidade de solução detergente.

\section{RESULTADOS}

Adotando as faixas de concentrações propostas neste trabalho, ou seja, 1,5 a 2,5\%(p/v) para as linhas frias, e 3,5 a 4,5\%(p/v) para o pasteurizador PET, e coletando os dados referentes a volume de equipamento, frequência de CIP, e custo de detergente, realizou-se uma estimativa da possível redução no consumo de detergente e da economia que pode ser alcançada (saving) em um período de um mês. Os resultados são mostrados na Tabela 2.

Tabela 2 - Estimativa de redução no consumo de detergente alcalino e saving mensal.

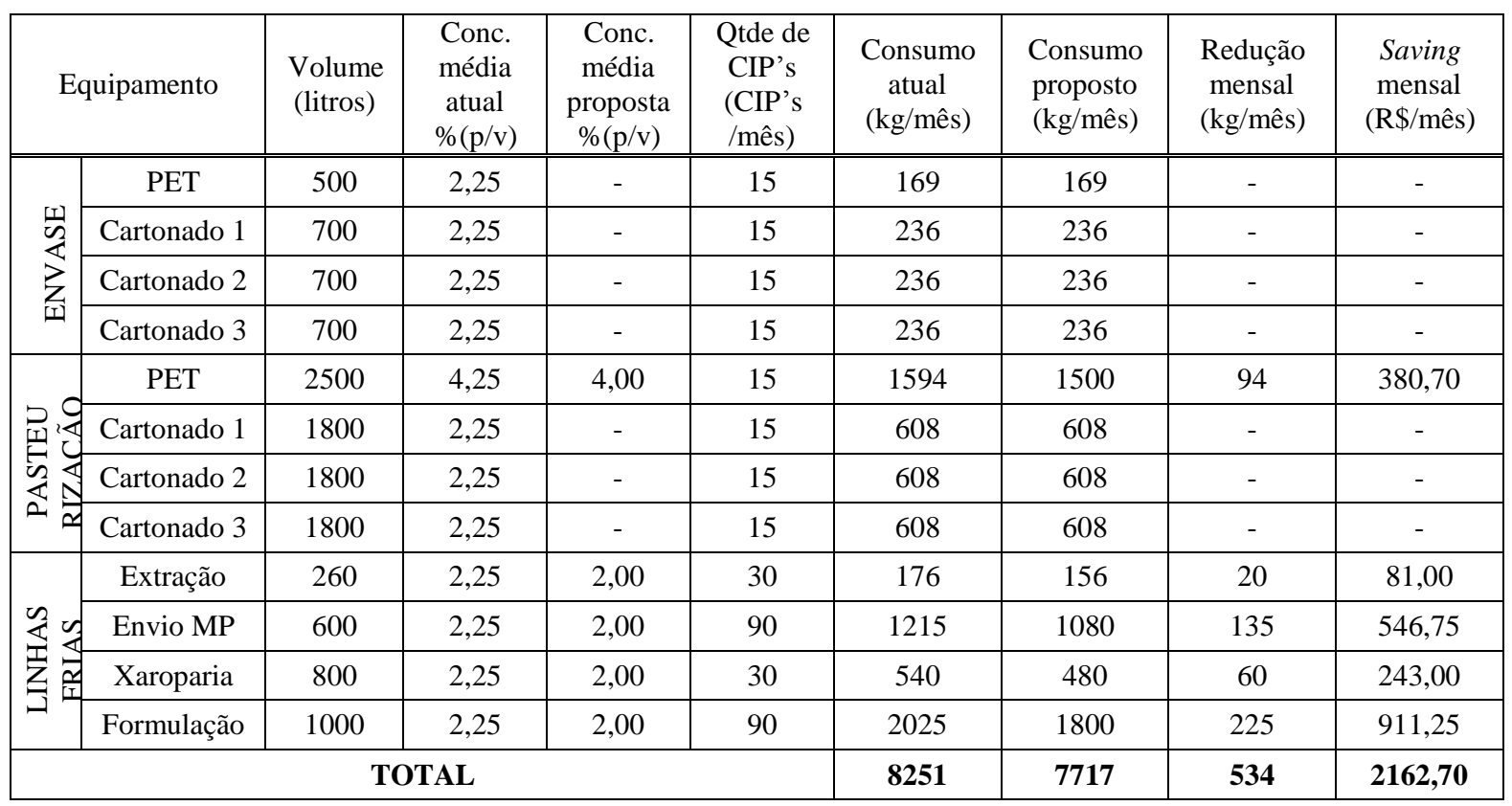




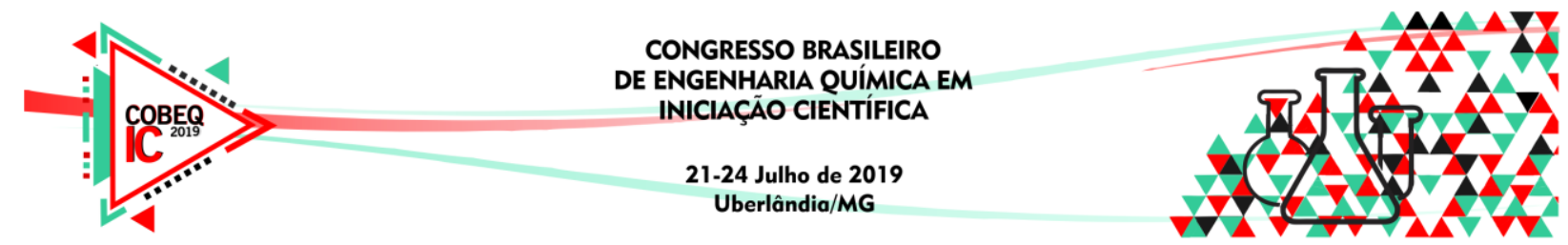

\section{CONCLUSÕES}

Antes de realizar uma análise da concentração hidróxido de sódio para limpeza CIP como havia sido proposta pelo trabalho, notou-se a necessidade de verificar os parâmetros de tempo, temperatura e vazão, conforme sugerido pelos estudos de Sinner.

Após perceber que as temperaturas, vazões e tempos de limpeza estavam de acordo com o que é proposto por diversos autores foram propostas melhorias nos parâmetros de concentração com o intuito de reduzir os custos sem afetar a qualidade do processo de limpeza.

Através das informações fornecidas sobre os equipamentos e frequência dos ciclos de limpeza, foi realizada uma estimativa da oportunidade de redução no consumo de detergente e saving mensal, caso as medidas propostas sejam adotadas e os resultados foram satisfatórios, com possibilidade de redução de aproximadamente quinhentos e trinta quilogramas de detergente por mês, correspondendo a uma economia mensal superior a dois mil reais.

\section{REFERÊNCIAS}

ANDRADE, N.J. Higiene na Indústria de Alimentos: avaliação e controle da adesão e formação de biofilmes bacterianos. São Paulo: Varela, 2008.

CHRISTIAN, G. K. Cleaning of carbohydrate and dairy protein deposits. PhD thesis, University of Birmingham, UK, 2004.

FRYER, P. J. and BIRD, M. R. Factors which affect the kinetics of cleaning dairy soils. Food Sci. Technol. Today 8(1) 36 $\pm 42,1994$.

LELIEVELD, H.; MOSTERT, T.; HOLAH, J. Handbook of hygiene control in the food industry. Cambridge: CRC, 2005.

PLETT, E. A. Cleaning of fouled surfaces. In: Fouling and Cleaning in Food Processing, Lund, D. B., Plett E., and Sandu C., eds, University of Wisconsin, Madison, WI, USA, $286-311,1985$.

TAMIME, A. Cleaning-in-Place: Dairy, Food and Beverage Operations. 3.rd. Oxford: Blackell Publishing, 2008.

TETRA PAK, The Orange Book, Tetra Pak Processing Systems AB, 2004.

TETRA PAK, A guide to cleaning technology in the food processing industry, Tetra Pak Processing Systems AB, 2015.

SINNER, H. Über das Waschen mit Haushaltwaschmaschinen, Hamburg, 1960. 